\title{
PRODUÇÃO DE MUDAS DE HORTALIÇAS ORGÂNICAS UTILIZANDO DIFERENTES SUBSTRATOS
}

\author{
JOSÉ ANTONIO FAVARIN ${ }^{1}$
}

VANESSA GOMES UENO

NEUZA MARIA DOS SANTOS OLIVEIRA ${ }^{3}$

\begin{abstract}
RESUMO
O presente trabalho foi conduzido no setor da olericultura orgânica, na Escola Técnica Engenheiro Herval Bellusci, Colégio Agrícola de Adamantina-SP. O estudo foi desenvolvido para avaliar a produção de mudas de rúcula, alface e almeirão em função de substratos alternativos. Os materiais utilizados para compor os tratamentos foram substrato preparado com compostagem orgânica $e$ húmus de minhoca. O delineamento experimental foi inteiramente casualizado no esquema fatorial 3 x 2 (cultura $x$ substratos). As variáveis analisadas foram à percentagem de germinação, altura da parte aérea, o número de folhas, o comprimento da planta e raiz e peso da massa fresca das plantas. Pode se observar valores superiores no tratamento com substrato preparado com compostagem orgânica quando comparado ao tratamento com húmus, apresentando comprimento médio das plantas de $190 \mathrm{~mm}$, altura da parte aérea média de $84,8 \mathrm{~mm}$ e comprimento médio de raiz $105 \mathrm{~mm}$, independentemente da hortaliça. Os resultados de uma forma geral demonstram uma superioridade do substrato preparado com compostagem o que pode ser explicado em função de suas características químicas e físicas que podem ser mais adequadas ao desenvolvimento das mudas de hortaliças. Pode se concluir que o substrato preparado com compostagem representa uma forma mais eficiente de produção de mudas de hortaliças no sistema orgânico do que o substrato gerado com húmus de minhoca.
\end{abstract}

PALAVRAS-CHAVE:Agricultura Orgânica. Horticultura.Substrato. Vermicompostagem

\section{SEEDLING PRODUCTION ORGANIC VEGETABLES USING DIFFERENT SUBSTRATES}

\section{ABSTRACT}

\footnotetext{
${ }_{1}^{1}$ Engenheiro Agronômo, Etec Engenheiro Herval Bellusci, agro.jfavarin@terra.com.br

${ }^{2}$ Licenciada em Biologia, Etec Engenheiro Herval Bellusci, vanessaueno@hotmail.com

${ }^{3}$ Ensino Fundamental, Etec Engenheiro Herval Bellusci, neuzaoliveira@yahoo.com.br
} 
The actual study was conducted in organic horticulture sector in the Technical School Engineer Herval Bellusci, Agricultural College of Adamantina - SP. The study was conducted in order to evaluate the production of arugula, lettuce and chicory seedlings on the basis of alternative substrates. The materials used to compose the treatments were substrate prepared with organic compost and earthworm humus. The experimental design was completely randomized in a factorial $3 \times 2$ scheme (culture $x$ substrates). The analyzed variables were percentage of germination, shoot height, number of leafs, root length, weight of fresh mass in the plants. Could can be observed superior values in the substrate prepared with organic compost treatment when compared to treatment with humus, which had an average plant length of $190 \mathrm{~mm}$, average shoot height of $84,8 \mathrm{~mm}$ and average root length $105 \mathrm{~mm}$, regardless of vegetable. The results in general show a superiority of substrate prepared with composting which can be explained in terms of its chemical and physical characteristics that can be most suitable for the development of vegetable seedlings. Can be concluded that the substrate prepared with compost enables a more efficient production of vegetable seedlings in the organic system that the substrate generated with earthworm humus.

KEY-WORDS: Organic Agriculture. Horticulture. Substrate. Vermicomposting

\title{
PRODUCCIÓN DE PLÁNTULAS VERDOR ORGÁNICOS UTILIZANDO SUSTRATOS DIFERENTES
}

\begin{abstract}
RESUMEN
El estudio se llevó a cabo en el sector de la horticultura orgánica en la Escuela Técnica Ingeniero Herval Bellusci, Colegio Agrícola de Adamantina -SP. El estudio fue desarrollado para evaluar la producción de plántulas de rúcula, lechuga y la achicoria sobre la base de sustratos alternativos. Los materiales utilizados para componer los tratamientos fueron el sustrato preparado con compost y humus de lombriz. El diseño experimental fue completamente al azar en un factorial $3 \times 2$ (culturas $\times$ sustratos). Las variables analizadas fueron porcentaje de germinación, altura de los brotes, número de hojas, longitud de la raíz, el peso de la masa fresca de las plantas. Puede se observar valores más altos en el tratamiento con sustrato preparado con abono orgánico en comparación con el tratamiento con humus, con longitud media de las plantas de $190 \mathrm{~mm}$, altura media de la parte aérea de $84,8 \mathrm{~mm}$ y longitud media de la raíz de105 mm, independientemente de vegetal. Los resultados en general muestran una superioridad del sustrato preparado con compost que puede ser explicado en términos de sus características químicas y físicas que pueden ser más adecuadas para el desarrollo de las plántulas de hortalizas. Se puede concluir que el sustrato preparado con compost permite una producción más eficiente de plántulas de hortalizas el sistema orgánico que el sustrato generado con humus de lombriz.
\end{abstract}

PALABRAS-CLAVE:Agricultura Orgánica. Horticultura. Sustrato. Lombricompostaje

\section{INTRODUÇÃO}

A produção de mudas de qualidade é uma das etapas mais importantes no cultivo de hortaliças (SILVA JÚNIOR et al., 1995), pois o desempenho produtivo em canteiros, tanto do ponto de vista nutricional, quanto do tempo necessário para a 
colheita dependem dessa fase. Portanto, para adequada produtividade de hortaliças orgânicas, é de suma importância a produção de mudas com qualidade, sendo fundamental a utilização de um substrato, que reúna em sua composição características físico-químicas que favoreçam o pleno desenvolvimento das mudas livres de fitopatógenos além de um baixo custo e alta disponibilidade de nutrientes.

Salvador (2000) define o substrato em horticultura, como um meio físico, natural ou sintético, onde se desenvolvem as raízes das plantas que crescem em um recipiente, com volume limitado. Dentre as qualidades que se espera de um substrato, pode-se citar: características físicas e químicas constantes; baixa densidade; boa capacidade de retenção de água e aeração; não se alterar quando submetido à esterilização; ser um meio rico em nutrientes com $\mathrm{pH}$ próximo a neutralidade; ser livre de pragas, doenças e propágulos de plantas daninhas entre outras.

Portanto, o substrato exerce uma influência marcante na arquitetura do sistema radicular (SPURR et al., 1982) e no estado nutricional das plantas, afetando profundamente a qualidade das mudas (CARNEIRO, 1983).

Dentre os sistemas de produção de mudas, o uso de bandejas de isopor tem se mostrado eficiente sob diversos aspectos, como economia de substrato e de espaço dentro da casa de vegetação, menor custo no controle de pragas e doenças, produção de mudas de alta qualidade obtendo-se assim plantas vigorosas e produtivas, devido aos sensíveis cuidados nas fases de germinação e emergência (MARQUES et al., 2003; PAGLIARINI et al., 2003).

Uma das principais funções do recipiente na produção de mudas é a de proteger as raízes dos danos mecânicos e da dissecação, promovendo sobrevivência no canteiro (QUEIROZ et al.,2010).

$\mathrm{Na}$ maioria dos países com horticultura avançada, uma das técnicas amplamente empregadas e que tem proporcionado aumentos substanciais na qualidade das mudas é o uso de substratos. Segundo Andriolo (1996) diversas matérias de origem orgânica e mineral podem ser empregados como substratos, sendo a disponibilidade e o custo, fatores determinantes para sua escolha. Os substratos também devem apresentar características físicas, químicas e biológicas apropriadas para que possa permitir pleno crescimento das raízes e da parte aérea 
(SETUBAL et al., 2000). Dentre as características desejáveis podemos citar a disponibilidade de nutrientes, teor de nutrientes, capacidade de troca de cátions, esterilidade biológica, areação, retenção de umidade, boa agregação às raízes e uniformidade. Outro material com potencial para ser utilizado como substrato para o desenvolvimento de plantas é o húmus produzido por minhocas. Este consiste em um produto estável e homogêneo, de coloração escura, inodoro, de textura leve, rico em nutrientes, formado a partir da transformação de resíduos orgânicos com a participação de minhocas (ANTONIOLLI et al. 2002 citado por SILVA et al., 2014).

Atualmente, encontram-se no mercado substratos formulados pelos mais variados tipos de materiais quanto à origem de seus componentes ou composição das misturas, sendo o húmus e o substrato comercial de hortaliças opções que vêm sendo utilizadas com frequência pelos produtores. Segundo, Correia et al. (2001) o húmus de minhoca caracteriza-se por proporcionar um adequado desenvolvimento vegetativo e do sistema radicular, capacidade de retenção de umidade, além de funcionar como eficiente fonte de matéria orgânica para as plantas.

Assim, objetivou-se com este trabalho, avaliar a produção de mudas de alface, rúcula e almeirão em função dos substratos produzidos a partir da compostagem com esterco fresco de curral ou inoculante líquido natural e bagaço de cana comparado com húmus de minhoca, todos produzidos de acordo com as normas da agricultura orgânica.

\section{MÉTODO DE ANÁLISE}

O trabalho foi desenvolvido na Etec Engenheiro Herval Bellusci, Colégio Agrícola de Adamantina - SP, durante os meses de março e abril de 2015 no setor da olericultura orgânica.

Utilizou-se uma estrutura de proteção de $85 \mathrm{~m}^{2}(17 \mathrm{~m} \times 5 \mathrm{~m}$ ), modelo capela,com cobertura de plástico transparente de 100 micra deespessura, aditivada contra raios ultravioletas. Os materiais usados para compor ostratamentos foram o húmus de minhoca e substrato feito a partir da produção da compostagem no setor, constituída por: Bagaço branco de cana (bagacilho), esterco de galinha, farinha de 
osso, cinza peneirada, torta de algodão ou farelos, ácido bórico, sulfato de zinco e inoculante líquido ou esterco bovino fresco de curral (Figura 1), onde se demonstra a montagem de uma camada da compostagem desenvolvida no setor de olericultura orgânica, a qual foi desenvolvida em um anel de aproximadamente 2 metros de diâmetro, onde podem ser produzidos aproximadamente $1000 \mathrm{~kg}$ por anel.

Aproximadamente sessenta dias após o início da compostagem foi produzido o substrato contento o composto peneirado $(100 \mathrm{~kg})$, farinha de osso (125g), calcário dolomítico $(250 \mathrm{~g})$, farelo de sojaou algodão (125g), cinza peneirada (1000g), ácido bórico (3g), sulfato de zinco (3g) e molibdato de sódio (1g).

A pilha permaneceupor aproximadamente 60 dias em período de cura, sendo revolvida por duas ou três vezes conforme alterações na temperatura e a necessidade de umidecê-la.

Após esse período a compostagem foi peneirada e encontrava-se em condições de ser utilizada para preparar o substrato.

Foramavaliadas as seguintes cultivares: Rúcula (Euruca Sativa), Alface Americana(Lactuca Sativa) e Almeirão Pão de Açúcar (Cichorium intybus) com pureza de $100 \%$ e índice de germinação de $95 \%$, segundo informações descritas pelo fabricante.

A semeadura ocorreu em bandejas de polipropileno com 128 células colocando-se sete sementes de rúcula e uma de alface e almeirão em cada célula a uma profundidade de $1 \mathrm{~cm}$. Foram utilizados $1772 \mathrm{~g}$ de substrato preparado com compostagem e $1518 \mathrm{~g}$ de húmus por bandeja.

Figura 1- Esquema da montagem de uma camada da compostagem no anel de dois metros de diâmetro.

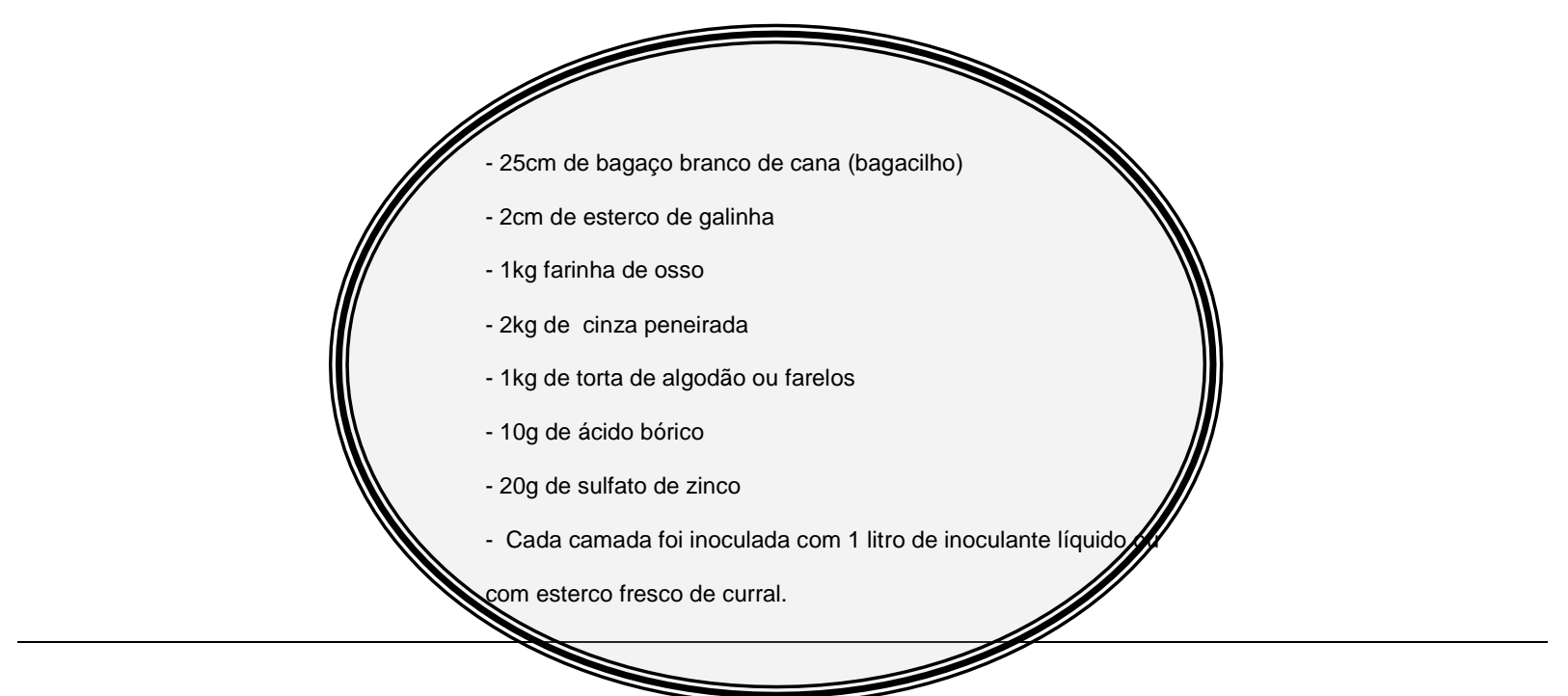


O início da germinação ocorreu aos 5 dias após a semeadura (DAS). As bandejas foram mantidas sobre as bancadas do viveiro, e a irrigação foi realizada por meio de microaspersão com uma lâmina diária de $6 \mathrm{~mm}$.

Decorridos 7 DAS foi avaliada a percentagem de germinaçãoe 23 dias após a semeadura, as seguintes características foram avaliadas: altura da parte aérea $(\mathrm{cm})$, o número de folhas por planta, comprimento da planta e da raiz $(\mathrm{mm})$ e peso da massa fresca (gramas) no total de quinze plantas por tratamento

A altura de planta e o comprimento das raízes foram determinados medindo do colo até o ápice da parte aérea e, do colo ao extremo da raiz, respectivamente, com auxílio de uma régua graduada. As raízes foram lavadas em água corrente para retirada da terra e impurezas. Em seguida, as amostras $(n=15)$ foram pesadas com auxílio de uma balança analítica de precisão para determinar massa fresca de cada amostra de hortaliça.

O delineamento experimental foi inteiramente casualizado no esquema fatorial $3 \times 2$, sendo três culturas e duas formas de substrato, com quinze repetições em cada tratamento.

Os dados obtidos foram submetidos à análise de variância pelo programa computacional Sistema Assistat versão 7.7 beta (SILVA, 2015) e as médias foram comparadas pelo teste Tukey a $5 \%$ de probabilidade.

\section{RESULTADOS E DISCUSSÃO}

Pode-se observar pela análise de variância utilizando-se o teste de Tukey $(P<0,05)$ com relação aos tratamentos húmus de minhoca e substrato preparado com compostagem na produção de hortaliças orgânicas que não houve diferença com relação à germinação das sementes em média 95\% independente do tratamento. Com relação ao comprimento das plantas, das raízes e altura da parte aérea houve diferença entre os tratamentos analisados (Tabela 1). 
Pode-se notar diferença entre os tratamentos com relação ao comprimento da planta, altura da parte aérea e o comprimento da raiz independente da hortaliça, notando uma superioridade do substrato preparado com compostagem orgânica.

Segundo Ensinas et al. (2011), avaliando diferentes combinações de substratos, observaram que o substrato comercial foram superiores ao uso do húmus, sendo suficientes para garantir o desenvolvimento das mudas de rúcula, o mesmo observado neste trabalho. Já, Handreck et al. (1999), os principais efeitos dos substratos manifestam-se sobre as raízes, acarretando influências principalmente sobre o crescimento da parte aérea. Smiderle et al. (2001) avaliando a eficiência do substrato comercial Plantmax® e sua combinação com solo e areia em experimento de produção de mudas de alface, pepino e pimentão, observaram que o Plantimax $\circledast$ proporcionou maior rapidez de emergência e maior altura da parte aérea, para as três hortaliças estudadas, podendo ser considerado como substrato apropriado para produção de mudas por apresentar menor densidade.

Tabela 1- Valores médios das variáveis analisadas em função dos tratamentos substrato e húmus vinte três dias após semeadura.

\begin{tabular}{crrr}
\hline Tratamentos & $\begin{array}{c}\text { Comprimento da } \\
\text { planta }(\mathbf{m m})\end{array}$ & $\begin{array}{c}\text { Altura de parte } \\
\text { aérea }(\mathbf{m m})\end{array}$ & $\begin{array}{c}\text { Comprimento da } \\
\text { raiz }(\mathbf{m m})\end{array}$ \\
\hline Substrato & $190^{\mathrm{a}}$ & $84,8^{\mathrm{a}}$ & $105^{\mathrm{a}}$ \\
\hline Húmus & $168^{\mathrm{b}}$ & $72,0^{\mathrm{b}}$ & $95,5^{\mathrm{b}}$ \\
\hline DMS & 0,73 & 0,44 & 0,55 \\
\hline CV\% & 9,85 & 13,61 & 13,25
\end{tabular}

$\overline{\mathrm{CV} \%}$ = coeficiente de variação; DMS= diferença mínima significativa. Médias seguidas por letras distintas minúsculas na coluna diferem entre si pelo teste Tukey a $5 \%$ de probabilidade.

O número de folhas apresentado no tratamento substrato preparado com compostagem para a alface e 0 almeirão foi de $5,8 \pm 1,4$ e $6,1 \pm 0,1$ e para 0 tratamento húmus foram de 5,5 $\pm 0,1$ e 5,7 $\pm 0,7$ apresentando maior quantidade de folhas no tratamento substrato preparado com compostagem (Figura 2).

Nota-se um maior número de folhas quando utilizado o substrato preparado com compostagem tanto para as mudas de alface como para as de almeirão. $O$ 
mesmo observado em trabalho produzido por Queiroz et. al, 2010 os quais utilizaram diferentes substratos e húmus na produção orgânica de mudas de alface, sendo nque os substratos com base em cama sobreposta de dejeto de suíno em maravalha apresentaram valores superiores em número de folhas em relação ao substrato comercial e o húmus (7,3; 4,58 e 6,5 respectivamente).

Figura 2 - Número de folhas de hortaliças aos 23 DAS utilizando substrato e húmus no sistema orgânico.

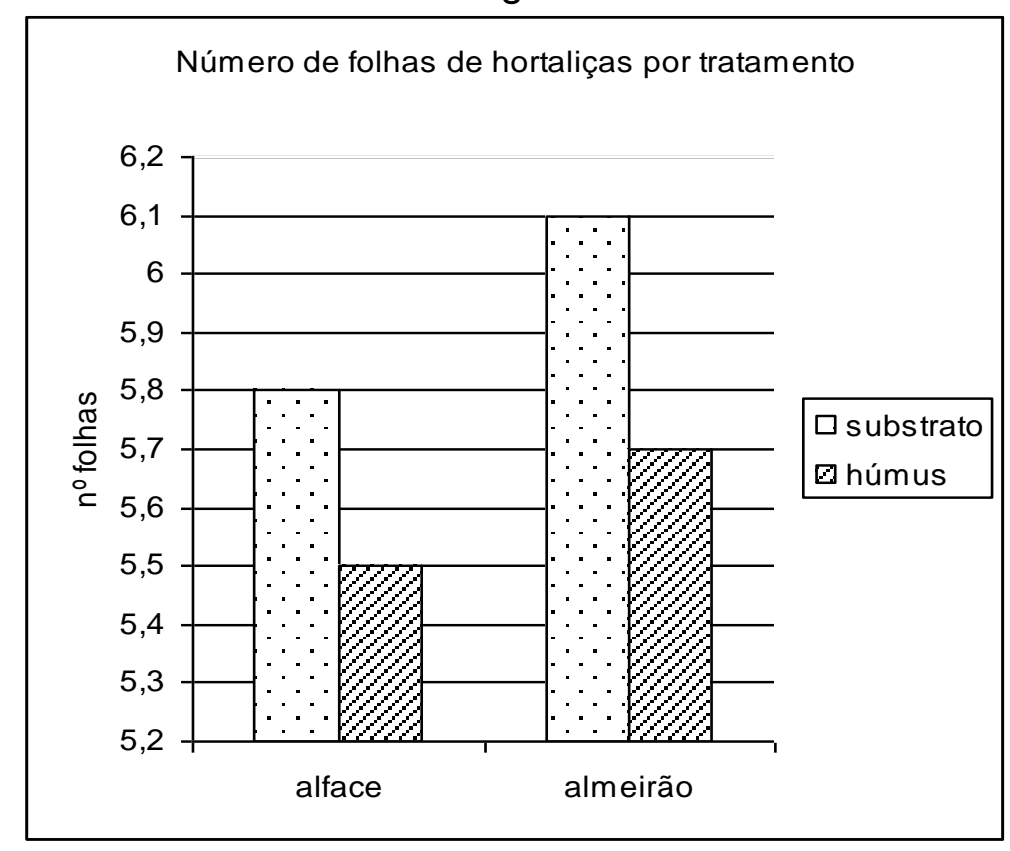

Com relação ao peso da massa fresca das plantas de acordo com tratamento substrato preparado com compostagem e húmus foi encontrado o seguinte resultado: rúcula $(1,6 \pm 0,1 \mathrm{~g}$ e $1,3 \pm 0,1 \mathrm{~g})$ alface $(1,2 \pm 0,3 \mathrm{~g}$ e $0,93 \pm 0,1 \mathrm{~g})$ e do almeirão $(1,0 \pm 0,1$ e $0,8 \pm 0,1)$. Observando um melhor peso da massa fresca para o tratamento substrato preparo com compostagem.

Os resultados de uma forma geral demonstram uma superioridade do substrato preparado com compostagem podendo ser explicada em função de suas características químicas e físicas mais adequadas ao desenvolvimento das mudas de hortaliças. 


\section{CONCLUSÃO}

Conclui-se que os substratos preparados com compostagem foram superiores ao uso do húmus na produção de mudas de hortaliças para uso em sistema orgânico de produção.

\section{REFERÊNCIAS BIBLIOGRÁFICAS}

ANDRIOLO, J.L. O cultivo de plantas com fertirrigação. Centro de Ciências Rurais, 47p., 1996.

CARNEIRO, JG de A. Variações na metodologia de produção de mudas afetam os parâmetros morfofisiológicos que indicam sua qualidade. Série técnica FUPEP, v.12, p. 9 a 54, 1983.

CORREIA, D.; CAVALCANTI JÚNIOR, A. T; COSTA, A. M. G. Alternativas de substratos para a formação de porta-enxertos de gravioleira (Annona muricata) em tubetes. Embrapa Agroindústria Tropical, 3p. (Comunicado Técnico, 67), 2001.

ENSINAS, S. C., MAEKAWA JUNIOR, M. T., CÂNDIDO, B. Desenvolvimento de mudas de rúcula em diferentes combinações de substrato, Revista Científica Eletrônica de Agronomia, Garça, v.18, n.1, p.1-7, jun, 2011.

HANDRECK, K.; BLACK, N. Growing media for ornamental plants and turf. Sydney: University of New South Wales Press, 448p,1999.

MARQUES PAA; BALDOTTO PV; SANTOS ACP; OLIVEIRA L. Qualidade de mudas de alface formadas em bandejas de isopor com diferentes números de células. Horticultura Brasileira, 21: 649-651, 2003.

PAGLIARINI, M.; AQUINO, A. M.; LEAL, M. A. Desenvolvimento de mudas de alface, para o cultivo orgânico, em diferentes tipos de substratos formulados a base de vermicomposto. In:Congresso Brasileiro de Agroecologia, 1., Porto Alegre, RS,1 cd-rom, 2003.

QUEIZOZ R. L; BAVUSO NETO, P.; SILVA, E. C. Produção orgânica de mudas de alface, Horticultura Brasileira, 28: S2772-S2779, 2010.

SALVADOR, E. D. Caracterização física e formulação de substratos para o cultivo de algumas ornamentais. ESALQ - USP, Piracicaba, 2002, 148p (Tese de Doutorado).

SETUBAL, J. W. C.; AFONSO NETO, F. Efeito de substratos alternativos e tipos de bandejas na produção de mudas de pimentão. Horticultura Brasileira, v.18, p. 593-594, 2000. (Suplemento).

SILVA, F. A. S., Assistat versão 7.7 beta. Homepage HTTP://www.asssistat.com, UFCG-Brasil, Atualizado em 01/04/215, visitado em 28/05/29015, 09:30h.

SILVA JÚNIOR, AA; MACEDO, SG; SLUKER, H. 1995. Utilização de esterco de peru na produção de mudas de tomateiro. Florianópolis: EPAGRI, 28 p. (Boletim Técnico, 73). 
SILVA, S., FERRAZ, R. M., FONSECA, R., PEREIRA, L. F. G., FERRAZ, R. M., GONÇALVES, L. D.Produção de mudas de alface (Lactuca sativa) utilizando diferentes substratos,VII Semana de Ciência e Tecnologia IFMG -campus Bambuí, 2014.

SMIDERLE, O. J.; SALIBE, A. B.; HAYASHI, A.H.; MINAMI, K. Produção de mudas de alface, pepino e pimentão em substratos combinando areia, solo e Plantmax ${ }^{\circledR}$. Horticultura Brasileira, v.19, p.253257, 2001.

SPURR, S.H.; BARNES, B.V. SPURR, S.H.; BARNES, B.V. Ecologia florestal, México: AGT, 1982. 